\title{
PENGARUH LATIHAN RANGE OF MOTION (ROM) MENGGENGGAM BOLA TERHADAP KEKUATAN OTOT EKSTREM ITAS ATAS PASIEN STROKE ISKEMIK
}

\author{
Hendri Budi, Netti, Yossi Suryarinilsih \\ (Poltekkes Kemenkes Padang)
}

\begin{abstract}
Stroke causes motor hemiparise disorders or weakness. Nursing intervention to overcome this is by doing range of motion (ROM) exercises grasping the ball. The purpose of the study was to identify the effect of ROM-grasping ball exercises on the strength of limb muscles in ischemic stroke patients. Quasi-experimental research type, one group pre-post test design. Research in the Neurosurgery Dr. M. Djamil Padang. The time of the research is October to December 2017. The intervention is ROM gripping ball exercises, namely rubber balls for 3 days followed by tennis balls for 2 days. Hold the ball firmly for 5 seconds then relax 10 seconds, practice repeated 10 times, frequency 3 times a day. The study population of all stroke patients in the Neurosurgery Dr. M. Djamil Padang. A sample of 10 people was obtained by purposive sampling that met the inclusion criteria. Data collection by measurement of muscle strength using Manual Muscle Testing (MMT). Data were computerized, analyzed by descriptive statistics and Wilcoxon test. The results of the study showed differences in upper limb muscle strength before and after the ROM exercise held the ball on the patient's shoulder ( $p$ value $=0.004$ ), on the elbow of the patient ( $p$ value = $0.000)$, on the patient's hand ( $p$ value $=0.000)$, and on the patient's finger ( $p$ value $=0.000$ ). It is recommended to nurses to implement the practice of grasping the ball to increase muscle strength of ischemic stroke patients and make it as a procedure for nursing intervention to patients to increase muscle strength.
\end{abstract}

Keywords: hold the ball; hemiparise; ischemic stroke

\section{PENDAHULUAN}

Stroke merupakan salah satu penyakit yang menyebabkan kerusakan/kecacatan permanen, dan merupakan penyebab utama morbiditas dan mortalitas. Hasil statistik memperkirakan bahwa 29\% klien stroke akan meninggal dalam waktu satu tahun, dengan $20 \%$ diantaranya meninggal dalam waktu tiga bulan, $25 \%$ mengalami ketergantungan, dan hanya $46 \%$ sisanya yang bisa hidup mandiri ${ }^{1}$.

Indonesia merupakan negara dengan jumlah penderita stroke terbesar di Asia. Di Indonesia, stroke merupakan penyakit nomor tiga yang mematikan setelah jantung dan kanker. Prevalensi stroke di Indonesia berdasarkan data Riset Kesehatan Dasar (Riskesdas) tahun 2013 sebesar 12,1 per mil yang terdiagnosis tenaga kesehatan. Stroke di Sumatera Barat berada pada urutan ke -12 yakni sebesar 12,2\%. Di kota Padang stroke berada pada urutan ke-15 yakni sebesar $(8,4 \% \circ)^{2}$. Angka kunjungan pasien pasca stroke di Poli Saraf RSUP Dr. M. Djamil Padang pada bulan Oktober sampai Desember 2015 cukup banyak yaitu 120 pasien ${ }^{3}$.

Salah satu manifestasi klinis stroke ialah gangguan motorik. Stroke dapat menyisakan kelumpuhan, terutama pada sisi yang terkena, timbul nyeri, sublokasi pada bahu, pola jalan 
yang salah dan masih banyak kondisi yang perlu dievaluasi oleh perawat ${ }^{4}$. Hemiparese merupakan kelemahan pada salah satu sisi anggota tubuh dan merupakan gangguan motorik yang paling sering dialami oleh klien stroke. Hal ini diakibatkan oleh penurunan tonus otot, sehingga pasien tidak mampu menggerakkan tubuhnya (imobilisasi). Immobilisasi yang tidak mendapatkan penanganan yang tepat, akan menimbulkan komplikasi berupa abnormalitas tonus, orthostatic hypotension, deep vein thrombosis dan kontraktur ${ }^{5}$. Salah satu intervensi keperawatan yang dapat dilakukan untuk mengatasi maslah hemiparese pada ekstremitas atas pasien stroke adalah dengan melakukan latihan range of motion (ROM) baik aktif maupun pasif. Intervensi keperawatan ini bertujuan untuk mempertahankan fungsi tubuh dan mencegah komplikasi. Latihan ROM merupakan salah satu rehabilitasi yang dapat diberikan pada pasien stroke ${ }^{6}$.

Salah satu latihan ROM aktif yaitu latihan menggenggam bola. Latihan genggaman pada tangan dapat dilakukan dengan menggunakan spherical grip karena paling mudah dan praktis digunakan, yaitu dengan memberikan benda berbentuk bulat (seperti bola tenis), lakukan koreksi pada jari-jari agar menggenggam sempurna, kemudian posisi wrist joint 45 derajat, selanjutnya berikan instruksi untuk menggenggam (menggenggam kuat) selama lima detik kemudian rileks, ini dilakukan pengulangan sebanyak tujuh kali ${ }^{7}$.

Belum ada penelitian yang dilaksanakan tentang latihan menggenggam bola untuk meningkatkan kekuatan otot pasien stroke di Ruang Rawat Saraf RSUP Dr. M. Djamil Padang. Oleh karena itu peneliti melakukan penelitian tentang pengaruh latihan Range of Motion (ROM) menggenggam bola terhadap kekuatan otot ekstremitas atas pada pasien stroke iskemik di Ruang Rawat Saraf RSUP Dr. M. Djamil Padang. Tujuan penelitian ini yaitu untuk mengidentifikasi perbedaan kekuatan otot ekstremitas atas sesudah dilakukan latihan ROM menggenggam bola pada pasien stroke iskemik di RSUP Dr M. Djamil Padang.

\section{METODE PENELITIAN}

Desain penelitian quasi-eksperimen dengan rancangan one group pre-post test. Penelitian ini menggunakan satu kelompok responden, yaitu kelompok intervensi sajayang diberikan perlakukan yaitu latihan menggenggam bola. Populasi penelitian seluruh pasien stroke di Ruang Saraf RSUP Dr. M. Djamil Padang. Sampel berjumlah 10 orang diperoleh secara purposive sampling yang memenuhi kriteria inklusi. Variabel pada penelitian ini adalah latihan menggenggam bola sebagai variabel independent yaitu latihan yang diberikan pada pasien stroke iskemik yang mengalami kelemahan otot ekstremitas atas yang terdiri dari menggenggam bola dengan menggunakan bola karet selama 3 hari yang dilanjutkan dengan latihan menggenggam bola dengan menggunakan bola tenis selama 2 hari dengan cara meletakkan bola karet diatas tangan yang mengalami kelemahan, 
kemudian jari-jari klien menggenggam sempurna, kemudian lakukan posisi wrist joint 45 derajat, dilanjutkan dengan menggenggam kuat selama 5 detik kemudian rileks selama 10 detik, diulangi latihan sebanyak 10 kali dengan frekwensi latihan 3 kali sehari pagi, siang dan sore. Variabel dependent yaitu kekuatan otot ekstremitas atas pasien stroke iskemik yaitu kemampuan otot ekstremitas atas pasien stroke iskemik melalui usaha yang maksimal untuk bergerak dan menggunakan kekuatannya dalam rentang waktu yang cukup lama.

Pengumpulan data melalui pengukuran kekuatan otot dengan menggunakan Manual Muscle Testing (MMT) dilakukan pada responden sebelum dan sesudah perlakuan. Data diolah secara komputerisasi, dianalisa secara univariat dengan menggunakan statistik deskriptif meliputi mean, standar deviasi, nilai minimum dan nilai maksimum, sedangkan analisa bivariat dilakukan untuk mengetahui pengaruh latihan ROM mengenggam bola terhadap peningkatan kekuatan otot pasien stroke iskemik. Peneliti melakukan uji normalitas dengan uji Shapiro-wilk. Data terdistribusi tidak normal sehingga dilakukan uji wilcoxon.

\section{HASIL PENELITIAN}

Karakteristik Responden pada penelitian ini dapat dilihat pada tabel berikut ini.

Tabel 1. Distribusi Frekuensi Responden Berdasarkan Jenis Kelamin Di Ruangan Saraf RSUP Dr. M. Djamil Padang Padang Tahun 2017

\begin{tabular}{lccc}
\hline Karakteristik Responden & Kategori & $\begin{array}{c}\text { Frekuensi } \\
\text { (f) }\end{array}$ & $\begin{array}{c}\text { Persentase } \\
\text { (\%) }\end{array}$ \\
\hline Jenis Kelamin & Laki-Laki & 3 & 30.0 \\
& Perempuan & 7 & 70.0 \\
\hline Umur & Middle Age (45 - 59 th) & 6 & 60.0 \\
& Elderly (60 - 74 th) & 4 & 40.0 \\
\hline Pendidikan & SD & 0 & 00.0 \\
& SLTP & 0 & 00.0 \\
& SLTA & 9 & 90.0 \\
& Perguruan Tinggi & 1 & 10.0 \\
\hline Pekerjaan & Tidak Bekerja & 2 & 20.0 \\
& IRT & 6 & 60.0 \\
& Pensiunan & 1 & 10.0 \\
& Swasta & 1 & 10.0 \\
\hline
\end{tabular}

Berdasarkan tabel.1 didapatkan karakteritik responden yaitu sebagian besar $(70 \%)$ pasien stroke berjenis kelamin perempuan, sebagian besar (60\%) berumur dewasa tua (45 59 tahun), hampir semua (90\%) berpendidikan SMA, lebih banyak $(60 \%)$ bekerja sebagai ibu rumah tangga. Kemudian hasil penelitian tentang perbedaan kekuatan otot ekstremitas atas sesudah dilakukan latihan ROM menggenggam bola pada pasien stroke iskemik di Ruang Saraf RSUP Dr M. Djamil Padang dapat dilihat pada tabel berikut : 


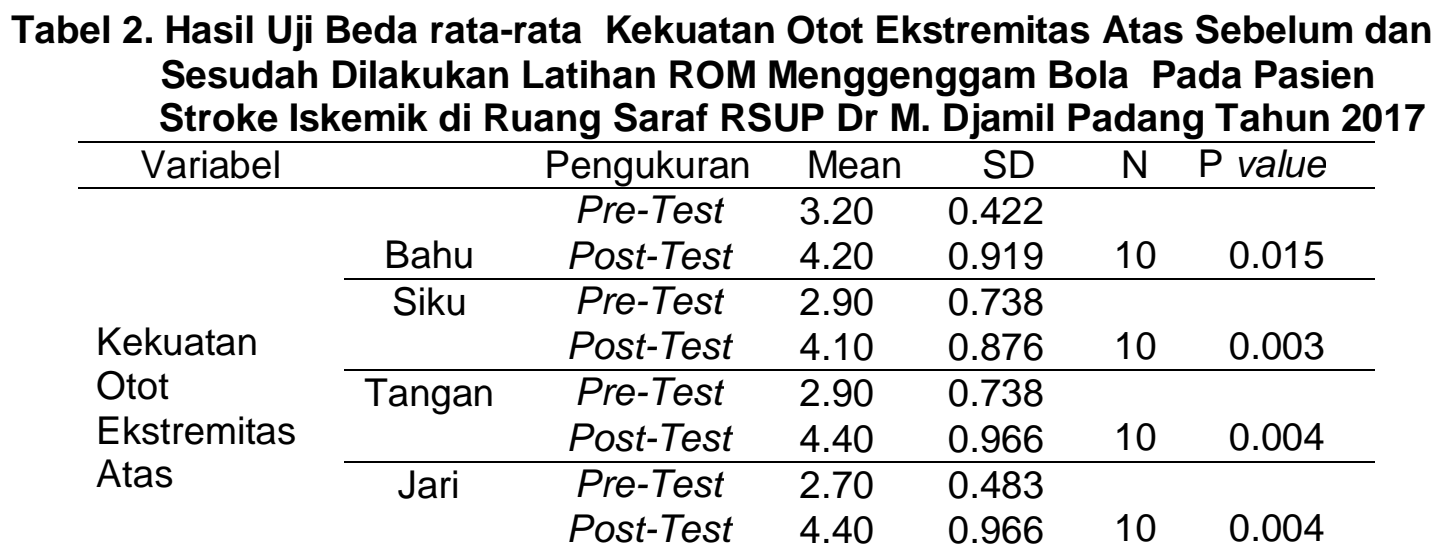

Hasil penelitian pada tabel 2 menunjukkan bahwa berdasarkan uji statistik dengan uji wilcoxon terdapat perbedaan kekuatan otot ekstremitas atas pada bagian bahu responden (nilai $p=0.004$ ), kemudian terdapat perbedaan antara kekuatan otot ekstremitas atas siku responden (nilai $p=0.000$ ), kemudian terdapat perbedaan antara kekuatan otot ekstremitas atas pada bagian tangan responden (nilai $p=0.000$ ), dan terdapat perbedaan antara kekuatan otot ekstremitas atas pada bagian jari responden (nilai $p=0.004$ ). Hal ini menunjukkan bahwa latihan ROM menggenggam bola dapat meningkatkan kekuatan otot ekstremitas atas pasien stroke iskemik yang mengalami kelemahan otot ekstremitas atas.

\section{PEMBAHASAN}

Karakteristik demografi pasien stroke di Ruang Saraf RSUP Dr M. Djamil Padang berdasarkan hasil penelitian terlihat pada tabel 1 didapatkan bahwa sebagian besar $(70 \%)$ pasien stroke berjenis kelamin perempuan, sebagian besar $(60 \%)$ berumur dewasa tua (45 59 tahun), hampir semua (90\%) berpendidikan SMA, lebih banyak $(60 \%)$ bekerja sebagai ibu rumah tangga. Hasil penelitian ini berbeda dengan hasil penelitian yang dilakukan Budi dan Bahar (2017) bahwa 75\% pasien stroke hemorragic berjenis kelamin laki - laki. 91,\% responden berumur dewasa tua ${ }^{8}$.

Hasil penelitian pada tabel 2 menunjukkan bahwa terdapat perbedaan antara kekuatan otot ekstremitas atas sebelum dan sesudah dilakukan latihan ROM menggenggam bola pada bagian bahu responden $(p$ value $=0.004$ ), kemudian terdapat perbedaan antara kekuatan otot ekstremitas atas sebelum dan sesudah dilakukan latihan ROM menggenggam bola pada bagian siku responden $(p$ value $=0.000)$, kemudian terdapat perbedaan antara kekuatan otot ekstremitas atas sebelum dan sesudah dilakukan latihan ROM menggenggam bola pada bagian tangan responden ( $p$ value $=0.000$ ), dan terdapat perbedaan antara kekuatan otot ekstremitas atas sebelum dan sesudah dilakukan latihan ROM menggenggam bola pada bagian jari responden $(p$ value $=0.000)$. Hal ini menunjukkan bahwa latihan ROM menggenggam bola dapat meningkatkan kekuatan otot ekstremitas atas pasien stroke iskemik yang mengalami kelemahan otot ekstremitas atas. 
Hasil penelitian ini sesuai dengan hasil penelitian lainnya yaitu penelitian yang dilakukan oleh Murtaqib (2013) yang menyimpulkan bahwa latihan ROM aktif berpengaruh terhadap perubahan rentang gerak sendi pada penderita stroke ${ }^{5}$. Selanjutnya sesuai pula dengan penelitian yang dilakukan oleh Winona Prok, Joudy Gessal dan L.S Angliadi (2016) tentang Pengaruh latihan gerak aktif menggenggam bola pada pasien stroke yang mendapatkan hasil ada perbedaan bermakna rata-rata kekuatan otot sebelum dan sesudah latihan $(p=$ 0,000). Kesimpulan penelitiannya bahwa ada pengaruh bermakna latihan gerak aktif menggenggam bola terhadap kekuatan otot tangan pada pasien stroke ${ }^{9}$. Selanjutnya penelitian ini sesuai juga dengan penelitian yang dilakukan oleh Cahyati (2012) yang mendapatkan hasil bahwa menunjukkan kekuatan otot meningkat pada kedua kelompok intervensi dan terdapat perbedaan yang signifikan antara kedua kelompok intervensi $(p=0,018, \alpha=0.05)^{10}$. Hasil penelitian ini juga sesuai dengan penelitian yang dilakukan oleh Anita, Pongantung, Ada dan Hingkam (2018) bahwa rentang gerak sendi pasien pasca stroke sebelum dilakukan latihan range of motion menunjukkan bahwa luas derajat rentang gerak sendi ekstremitas atas seperti sendi peluru, sendi engsel, dan sendi kondiloid mengalami keterbatasan, namun sesudah dilakukan latihan range of motion menunjukkan bahwa luas derajat rentang gerak sendi meningkat ${ }^{11}$.

Pasien stroke iskemik memerlukan latihan ROM ini karena pasien stroke dapat mengalami kelemahan anggota gerak yang salah satunya yaitu extremitas atas. Manifestasi klinik yang sering terjadi pada pasien stroke diantaranya adalah kelemahan pada alat gerak. Tanda dan gejala ini biasanya terjadi secara mendadak, fokal dan mengenai satu sisi ${ }^{12}$. Otot yang mengalami hemiparise perlu dilakukan rangsangan agar kekuatan otot meningkat. Otot skelet harus dirangsang oleh sel syaraf untuk berkontraksi. Satu unit motor diinervasi oleh satu neuron. Jika sel otot tidak dirangsang, sel akan mengecil (atrofi) dan mati, bahkan kadang kadang diganti dengan jaringan konektif yang irreversible ketika rusak ${ }^{13}$. Oleh karena itu pasien stroke yang mengalami kelemahan otot extremitas perlu dilakukan latihan ROM. Hal ini sesuai dengan yang dinyatakan Pinzon, Rizaldy dan Asanty (2010) bahwa latihan ROM merupakan salah satu rehabilitasi yang dapat diberikan pada pasien stroke ${ }^{6}$.

Latihan ROM ini dapat meningkatkan kemampuan pasien stroke iskemik untuk menggerakkan persendian secara normal dan lengkap untuk meningkatkan massa otot dan tonus otot. ROM merupakan latihan yang digunakan untuk mempertahankan atau memperbaiki tingkat kesempurnaan kemampuan untuk menggerakkan persendian secara normal dan lengkap untuk meningkatkan massa otot dan tonus otot. Latihan ROM dapat menggerakkan persendian seoptimal dan seluas mungkin sesuai kemampuan seseorang dan tidak menimbulkan rasa nyeri pada sendi yang digerakkan. Adanya pergerakan pada persendian akan menyebabkan terjadinya peningkatan aliran darah ke dalam kapsula sendi. Ketika sendi digerakkan, permukaan kartilago antara kedua tulang akan saling bergesekan. 
Kartilago banyak mengandung proteoglikans yang menempel pada asam hialuronat yang bersifat hidrophilik. Adanya penekanan pada kartilago akan mendesak air keluar dari matrik kartilago ke cairan sinovial. Bila tekanan berhenti maka air yang keluar ke cairan sinovial akan ditarik kembali dengan membawa nutrisi dari cairan ${ }^{10}$.

Hasil penelitian ini menunjukkan bahwa latihan ROM menggenggam bola dengan menggunakan bola karet selama 3 hari yang dilanjutkan dengan latihan menggenggam bola dengan menggunakan bola tenis selama 2 hari dengan cara meletakkan bola karet diatas tangan yang mengalami kelemahan, kemudian jari-jari klien menggenggam sempurna, kemudian lakukan posisi wrist joint 45 derajat, dilanjutkan dengan menggenggam kuat selama 5 detik kemudian rileks selama 10 detik, diulangi latihan sebanyak 10 kali dengan frekwensi latihan 3 kali sehari pagi, siang dan sore dapat meningkatkan kekuatan otot ekstremitas atas pasien stroke iskemik yang mengalami kelemahan otot ekstremitas atas.

Latihan ROM menggenggam bola ini perlu dilakukan berulang. Menurut Sudarsono (2011) bahwa faktor penting yang dapat meningkatkan kekuatan otot adalah dengan latihan. Dengan latihan secara teratur akan menimbulkan pembesaran (hipertrofi) fibril otot. Semakin banyak latihan yang dilakukan maka semakin baik pula pembesaran fibril otot itulah yang menyebabkan adanya peningkatan kekuatan otot. Untuk mencapai peningkatan kekuatan otot dengan baik, diperlukan latihan yang disusun dan dilaksanakan dengan program latihan yang tepat. Agar latihan yang dilakukan dapat mencapai hasil yang sesuai dengan yang diharapkan, program latihan yang disusun untuk meningkatkan kekuatan otot harus memperhatikan faktor-faktor tersebut ${ }^{14}$.

Dengan melakukan latihan ROM dengan menggenggam bola karet dan bola tenis tersebut, maka akan terjadi kontraksi dan relaksasi otot, maka akan semakin banyak serabut otot yang teraktivasi yang akan menghasilkan kekuatan otot yang semakin besar. Kekuatan otot sangat berhubungan dengan sistem neuromuskuler yaitu seberapa besar kemampuan system saraf mengaktifasi otot untuk melakukan kontraksi. Dengan demikian semakin banyak serabut otot teraktivasi, maka semakin besar pula kekuatan yang dihasilkan oleh otot tersebut ${ }^{7}$. Sesuai pula dengan pendapat Saryono (2011) bahwa latihan beban atau hambatan/tahanan, akan merangsang pembesaran sel akibat sintesis miofilamen yang banyak. Latihan daya tahan menghasilkan peningkatan mitokondria, glikogen dan densitas kapiler ${ }^{13}$.

Dengan demikian, latihan ROM menggenggam bola ini perlu diketahui oleh pasien, perawat, dan keluarga yang terlibat langsung dalam perawatan pasien stroke iskemik yang mengalami hemiparise ekstremitas atas agar dapat melaksanakan latihan tersebut agar kekuatan otot pasien dapat meningkat. Perawat dapat memberikan pendidikan kesehatan dengan memberikan latihan kepada pasien dan keluarga yang merawat pasien tentang latihan menggenggam bola untuk meningkatkan kekuatan otot ekstremitas atas pasien 
stroke yang mengalami hemiparise. Latihan ini dapat diberikan perawat dengan melakukan persiapan seperti persiapan modul latihan, kemudian menjelaskan kepada pasien dan keluarga tujuan, manfaat dan waktu latihan. Selanjutnya perawat menjelaskan prosedur latihan yaitu menggenggam bola dengan menggunakan bola tenis selama 2 hari dengan cara meletakkan bola karet diatas tangan yang mengalami kelemahan, kemudian jari-jari klien menggenggam sempurna, kemudian lakukan posisi wrist joint 45 derajat, dilanjutkan dengan menggenggam kuat selama 5 detik kemudian rileks selama 10 detik, diulangi latihan sebanyak 10 kali dengan frekwensi latihan 3 kali sehari pagi, siang dan sore. Sesuai dengan penelitian Agonwardi dan Hendri Budi bahwa diharapkan pendidikan kesehatan tentang latihan ROM sebagai salah satu intervensi didalam pemberian pelayanan asuhan keperawatan dan menjadikan pendidikan kesehatan tentang latihan ROM sebagai protap atau standar asuhan keperawatan kepada pasien stroke dan keluarganya ${ }^{15}$.

\section{SIMPULAN DAN SARAN}

Hasil penelitian menunjukkan bahwa terdapat perbedaan kekuatan otot ekstremitas atas pada bagian bahu (nilai $p=0.004$ ), pada bagian siku (nilai $p=0.000$ ), pada bagian tangan (nilai $p=0.000$ ), dan pada bagian jari (nilai $p=0.004$ ) pasien. Berdasarkan hasil penelitian tersebut maka kesimpulan penelitian ini yaitu terapi latihan ROM menggenggam bola dengan menggunakan bola karet selama 3 hari yang dilanjutkan dengan latihan menggenggam bola dengan menggunakan bola tenis selama 2 hari dengan cara meletakkan bola karet diatas tangan yang mengalami kelemahan, kemudian jari-jari klien menggenggam sempurna, kemudian lakukan posisi wrist joint 45 derajat, dilanjutkan dengan menggenggam kuat selama 5 detik kemudian rileks selama 10 detik, diulangi latihan sebanyak 10 kali dengan frekwensi latihan 3 kali sehari pagi, siang dan sore dapat meningkatkan kekuatan otot ekstremitas atas pasien stroke iskemik yang mengalami kelemahan otot ekstremitas atas.

Peneliti menyarankan kepada kepala ruangan Saraf RSUP Dr M. Djamil Padang agar dapat menerapkan latihan menggenggam bola pada pasien stroke yang mengalami kelemahan otot ekstremitas atas serta menjadikan latihan menggenggam bola yaitu mengenggam bola karet dan bola tenis sebagai protap atau standar asuhan keperawatan kepada pasien stroke yang mengalami hemiparise ekstremitas atas untuk meningkatkan kekuatan otot pasien. 


\section{DAFTAR PUSTAKA}

1. Lloyd-jones D, Adams RJ, Brown TM, et al. Heart Disease and Stroke Statistics - 2010 Update A Report From the American Heart Association. 2010:46-215. doi:10.1161/CIRCULATIONAHA.109.192667

2. Kemenkes R. Laporan Riset Kesehatan Dasar (Riskesdas) Tahun 2013.; 2014.

3. RSUP PDMJ. Profil Penyakit.; 2016.

4. Suzanne C. Smeltzer, Brenda G. Bare, Janice L. Hinkle KHC. Brunner \& Suddarth's Texbook of Medical-Surgical Nursing. (12 Th Ed).; 2014.

5. Murtaqib M. Pengaruh Latihan Range Of Motion (ROM) Aktif Terhadap Perubahan Rentang Gerak Sendi Pada Penderita Stroke Di Kecamatan Tanggul Kabupaten Jember. IKESMA J IImu Kesehat Masy. 2013;9 No 2.

6. Pinzon, Rizaldy, Asanti L. Awas Stroke! Pengertian, Gejala, Tindakan, Perawatan Dan Pencegahan.Yogyakarta: ANDI.; 2010.

7. Irfan M. Fisioterapi Bagi Insan Stroke. Yogyakarta: Graha IImu. 2010.

8. Budi H, Bahar I. Faktor Resiko Stroke Hemorragic Pada Pasien Usia Produktif. J Sehat Mandiri. 2017;12(2):29-36.

9. Winona Prok, Joudy Gessal L. A. Pengaruh latihan gerak aktif menggenggam bola pada pasien stroke diukur dengan handgrip dynamometer. J e-Clinic. 2016;4(April).

10. Cahyati Y, Nurachmah E, Hastono SP. Perbandingan Peningkatan Kekuatan Otot Pasien Hemiparise Melalui Latihan Range Of Motion Unilateral dan Bilateral. $J$ Keperawatan Indones Vol 16 No 1 Tahun 2013. 2013;16(1):40-46.

11. Anita. F., Pongantung. H., P. V. Ada, HV. Pengaruh Latihan Range Of Motion Terhadap Rentang Gerak Sendi Ekstremitas Atas Pada Pasien Pasca Stroke di Makassar. 2018.

12. Lemone, P., Burke, K., Dwyer, T., Levett-Jones, T., Moxham, L. J., Reid-Searl, K., Berry, K., Carville, K., Hales, M., Knox, N., Luxford, Y. \& Raymond D. Medical-Surgical Nursing: Critical Thinking in Client Care. Frenchs Forest, N.S.W: Pearson Australia.; 2011.

13. Saryono. Biokimia Otot. Satu. Yogyakarta: Nuha Medika; 2011.

14. Sudarsono S. Penyusunan Program Pelatihan Berbeban untuk Meningkatkan kekuatan (Slamet Sudarsono). Spirit, J IIm. 2011;11(3):31-43.

15. Agonwardi, Budi H. Pengaruh Pendidikan Kesehatan Latihan Range Of Motion (ROM) Terhadap Ketrampilan Keluarga Melakukan ROM Pasien Stroke. J Endur Kaji IIm Probl Kesehat. 2016;1(February):47-54. 